ARTICLE HISTORY: January: 17, 2021 Accepted: March 12, 2021 Published: March 19, 2021

\title{
APPLICATION OF BENCHMARKING TECHNOLOGY FOR MANAGING THE DEVELOPMENT OF AN EDUCATIONAL ORGANIZATION
}

\author{
Khakimyanova Irina Viktorovna \\ MAOU "Secondary School No. 9", Director, \\ FSBEI HE "SUSPU", student
}

\section{ПРИМЕНЕНИЕ ТЕХНОЛОГИИ БЕНЧМАРКИНГА ДЛЯ УПРАВЛЕНИЯ РАЗВИТИЕМ ОБРАЗОВАТЕЛЬНОЙ ОРГАНИЗАЦИЕЙ}

\author{
Хакимьянова Ирина Викторовна \\ МАOУ «СОШ №9», директор, \\ ФГБОУ ВО «ЮУрГГПУ», студентка
}

\begin{abstract}
This article will discuss benchmarking as an innovative technology for managing the development of an educational organization. The purpose of our work is to prove that the application of this technology is relevant for schools.

Аннотация. В данной статье пойдет речь о бенчмаркинге как инновационной технологии управления развитием образовательной организацией. Цель нашей работы состоит в том, чтобы доказать, что применение данной технологии актуально для школ.

Key words: benchmarking, technology, development management of an educational organization, Educational organization development program

Ключевые слова: бенчмаркинг, технология, управление развитием образовательной организацией, Программа развития образовательной организации
\end{abstract}

Современные реформы образования в России требуют от руководителей школ поиска новых инновационных технологий, методов, инструментов управления, позволяющих рационально использовать собственные ресурсы, формировать эффективную систему управления развитием общеобразовательными организациями, быть конкурентоспособными и удовлетворять запросы всех участников образовательных отношений.

Мы провели собственное научное исследование и пришли к выводу, что для управления развитием образовательной организацией применима такая технология как бенчмаркинг. В данной статье продемонстрируем нашу работу в данном направлении.

Проанализировав различные определения этого понятия, приходим к тому, что бенчмаркинг - это маркетинговый инструмент поиска инноваций в других организациях с целью улучшения собственной работы.

Многие предприятия и организации за рубежом практикуют данную технологию уже давно. В России бенчмаркинг не нашел широкого применения. Мало распространен в бизнесе, редко используется в промышленности и строительстве. В отрасли здравоохранения используется применительно при оценке новых способов лечения, качества оказания медицинских услуг. Есть опыт применения для развития учреждений высшего образования, но применительно к образовательной организации бенчмаркинг достаточно не исследован.

Научная новизна исследования заключается в повышении эффективности управления развитием образовательной организации на основе концепции бенчмаркинга. Что это даст школе? Какой результат получим? Прежде всего, применение бенчмаркинга позволяет «увидеть себя с другой стороны», поможет выявить сильные и слабые стороны школы, получить объективную оценку деятельности. Инновация тем и хороша, что идет развитие образовательного и воспитательного процессов, а значит совершенствование качество получаемых обучающимися образовательных и воспитательных услуг. В условиях жесткой конкуренции это один из главных показателей. Немаловажным фактом считается и то, что бенчмаркинг позволяет заменить традиционное планирование на совершенно новое, опирающееся на анализ показателей лучших практик. Также плюсом может служить то, что, лидируя по каким-то параметрам, образовательная организация может наметить свои долгосрочные перспективы. Таким образом, бенчмаркинг позволяет разработать единый подход к стратегии образовательной организации, провести системный анализ собственной работы и деятельности конкурентов [1, с. 76].

Поэтому мы можем точно сказать, что на сегодняшний день необходима разработка стандартов внедрения технологии бенчмаркинга в общеобразовательные организации, так как нет системного подхода к формированию бенчмаркингового процесса в школах. Руководители образовательных организаций не умеют 
применять на практике теоретические основы менеджмента, не знают современные технологии управления, не понимают значимость слаженной командной работы администрации и других участников образовательных отношений. В школе недостаточное внимание уделяется вопросам выбора системы критериев оценки, эффективности Программы развития образовательной организации, системно-ориентированному анализу деятельности школы, процедурам внутренней оценки качества образования (далее ВСОКО) в ориентире положительного опыта конкурентов. Не созданы школьные команды, способные реализовывать процесс бенчмаркинга, для составления и внедрения Программы развития образовательной организацией, ВСОКО. Это приводит к тому, что не принимаются правильные управленческие решения для повышения конкурентоспособности школ, их инновационности и общественного признания. Говоря об управлении школой, мы подразумеваем такое управление, при котором осуществляется системный подход к проблемноориентированному анализу учебно-воспитательной работы, продуманному планированию, применению инновационных управленческих технологий, реализации планов, осуществление контроля деятельности. Все это отражается в главном нормативном документе учебных заведений - Программе развития.

Чтобы доказать правоту наших высказываний, мы решили проанализировать действующие программы развития школ города Челябинска для определения следующих показателей: актуальности, проблемности, инновационности, конкурентоспособности, управляемости, контролируемости, а также структуризации. Для исследования использовали метод анализа документов, контент-анализ, сравнительный анализ. Выбрали 46 образовательных организаций города Челябинска, среди которых общеобразовательные школы, гимназии, лицеи, и просмотрели их программы развития.

Опираясь на представления о процессе ее разработки, названных выше критериев, был сделан ряд выводов. В 100\% проанализированных образовательных организациях сделан анализ предыдущей программы развития, но проблемно-ориентированным его можно назвать только у 8,7\% школ. Выявлено, что только в 32,6\% программах развития провели SWOT и/или PEST анализ, позволяющий выявить собственные проблемы, возможности, риски. $100 \%$ образовательных организаций выбирают для реализации своего развития подпрограммы с описанием целей, задач, планом (дорожной картой) и ожидаемыми результатами, прописывают достижение индикативных показателей. Совершенствование образовательной системы по результатам внутренней системы оценки качества образования отражено всего лишь в 13\% Программах развития. У 26\% школ в Программах спланированы процессы инновационного управления образовательной организацией. Но при этом очень незначительная часть школ, всего 13\% создают собственную инновационную практику. В $37 \%$ Программах ставится акцент на создание качественного конкурентного образования и только у 8\% организаций данный документ является реальным инструментом развития школы как открытой инновационной образовательной системы, обладающей высокой конкурентоспособностью. В программах развития присутствует анализ внешних партнеров, но целеполагание не основывается на анализе программ развития других сфер - культуры, спорта, науки, бизнеса. Можно предположить, что школы не видят необходимости развития в этих направлениях и не рассматривают городское сообщество и городскую среду в качестве ресурса для развития. Только одна школа выбрала инновационную идею развития образовательной деятельности через выявление конкурентоспособности и уникальности других учреждений. Ни одна школа не использовала лучший опыт деятельности других образовательных организаций для обеспечения более высокого качества образования.

Сделанные в результате анализа выводы указывают на ряд проблем, связанных с разработкой Программ развития образовательной организации. Есть разработчики, которые формально подходят к этому процессу, не владеют необходимыми для этого компетенциями. Многие недооценивают возможности использования инновационных технологий в управлении образованием. А существуют и такие школьные команды, которые напрямую не заявляют о своих конкурентных отношениях с другими общеобразовательными организациями, которые демонстрируют высокие результаты деятельности.

Мы понимаем, что невозможно улучшить сразу все управление развитием, так как это широкий спектр деятельности. Поэтому необходимо выделить приоритетные направления в развитии школой. В государственной программе Российской Федерации «Развитие образования» на 2018-2025 годы целью номер один - является качество образования, которое характеризуется: обеспечением глобальной конкурентоспособности российского образования, вхождением Российской Федерации в число 10 ведущих стран мира по качеству общего образования. Основной целью Государственной программы Челябинской области «Развития образования Челябинской области» на 2018-2025 годы является создание условий для эффективного развития образования, направленного на обеспечение доступности качественного образования, соответствующего требованиям современного инновационного социально ориентированного развития Челябинской области. В Федеральном законе «Об образовании в Российской Федерации» $273-Ф 3$ ст.28 п.13 общеобразовательная организация должна обеспечить функционирование внутренней системы оценки качества образования. В Приказе Министерства просвещения Российской Федерации от 13.03.2019 года № 114 утверждены показатели, которые характеризуют оценку качества условий осуществления образовательной деятельностью по основным общеобразовательным программам. 
Мы приходим к выводу, что на сегодняшний день одним из важнейшим направлением развития образовательной организации является разработка и функционирование внутренней оценки качества образования (далее ВСОКО). Поэтому необходимо продумать процесс внедрения бенчмаркинга в общеобразовательные организации для разработки и функционирования внутренней системы оценки качества образования.

В нашей работе мы использовали самые разнообразные методы, которые позволили решить актуальные задачи. С целью познания структуры образовательной организации, ее отдельных сторон использовали анализ, это позволило нам серьезнее изучить объект и сделать вывод о полученных фактах. Из всех известных видов анализа предпочли сравнительный анализ, причинно-следственный анализ, анализ показателей эффективности. Анализ управленческой деятельности образовательных организаций провели на основе изучения их результатов самообследования, Программ развития образовательных организаций, нормативных локальных актов, в том числе по ВСОКО.

\section{СПИСОК ЛИТЕРАТУРЫ:}

1. Алексунин В. А. Маркетинг в отраслях и сферах деятельности: учеб.пособие . - М. : Маркетинг, 2007. $-516 \mathrm{c}$.

2. Постановление Правительства РФ от 26.12.2017 года № 1642 (ред. от 29.03.2019) "Об утверждении государственной программы Российской Федерации «Развитие образования» (с изм. и доп., вступ. в силу с 12.04.2019)

3. Постановление Правительства Челябинской области от 28.12.2017 года № 732-П «О Государственной программе Челябинской области «Развития образования Челябинской области» на 2018-2025 годы»

4. Протасов, Д.В. П831 Теория и практика применения технологии бенчмаркинга для улучшения качества деятельности организации : монография /Д.В. Протасов. - Тамбов : Изд-во Тамб. гос. техн. унта, 2009. -80 с. - 100 экз. - ISBN 978-5-8265-0808-4., с.1)

5. Федеральный закон «Об образовании в Российской Федерации» 273-Ф3

\section{References}

1. Aleksunin VA Marketing in industries and spheres of activity: ucheb.posobiye. - M.: Marketing, 2007 .-- 516 p.

2. Decree of the Government of the Russian Federation of December 26, 2017 No. 1642 (as amended on March 29, 2019) "On approval of the state program of the Russian Federation" Development of Education "(as amended and supplemented, entered into force on April 12, 2019)

3. Decree of the Government of the Chelyabinsk Region of December 28, 2017 No. 732-P "On the State Program of the Chelyabinsk Region" Development of Education in the Chelyabinsk Region "for 2018-2025"

4. Protasov, D.V. P831 Theory and practice of using benchmarking technology to improve the quality of an organization's activities: monograph : monografiya /D.V. Protasov. - Tambov : Izd-vo Tamb. gos. tekhn. un-ta, 2009. -80 p. - 100 ekz. - ISBN 978-5-8265-0808-4., p.1)

5. Federal Law "On Education in the Russian Federation" 273-FZ 